\title{
Assessment of lectin-binding analysis for in situ detection of glycoconjugates in biofilm systems
}

\author{
Thomas R. Neu, ${ }^{1}$ George D. W. Swerhone ${ }^{2}$ and John R. Lawrence ${ }^{2}$ \\ Author for correspondence: Thomas R. Neu. Tel: +49 3918109 800. Fax: +49 3918109150. \\ e-mail:neu@gm.ufz.de
}

1 Department of Inland Water Research Magdeburg, UFZ Centre for Environmental Research, Leipzig-Halle, Brueckstrasse 3A, 39114 Magdeburg, Germany

2 National Water Research Institute, Saskatoon, Saskatchewan, Canada
An assessment of lectin-binding analysis for the characterization of extracellular glycoconjugates as part of the extracellular polymeric substances in environmental microbial communities was performed using fully hydrated river biofilms. The applicability of the method was evaluated for single, dual and triple staining with a panel of fluor-conjugated lectins. It was shown that lectin-binding analysis was able to stain glycoconjugates within biofilm communities. Lectin staining also demonstrated spatial heterogeneity within the biofilm matrix. Furthermore, the application of two or even three lectins was possible if suitable combinations were selected. The lectin-binding analysis can be combined with general nucleic acid stains to collect both nucleic acid and glycoconjugate signals. The effects of incubation time, lectin concentration, fluor labelling, carbohydrate inhibition, order of addition and lectin interactions were studied. An incubation time of $\mathbf{2 0}$ min was found to be sufficient for completion of lectin binding. It was not possible to ascertain saturating concentration for individual lectins, therefore a standard concentration was used for the assay. Carbohydrate inhibition tests indicated that fluorescein isothiocyanate (FITC)-conjugated lectins had more specific binding characteristics than tetramethyl rhodamine isothiocyanate (TRITC)- or cyanine dye (CY5)-labelled lectins. The order of addition and the nature of the fluor conjugate were also found to influence the binding pattern of the lectins. Therefore the selection of a panel of lectins for investigating the EPS matrix must be based on a full evaluation of their behaviour in the biofilm system to be studied. Despite this necessity, lectin-binding analysis represents a valuable tool to examine the glycoconjugate distribution in fully hydrated biofilms. Thereby, chemical heterogeneities within extracellular biofilm locations can be identified in order to examine the role (e.g. sorption properties,

microenvironments, cell-extracellular polymeric subtance interactions) of the extracellular polymeric substances in environmental biofilm systems.

Keywords: biofilms, lectins, extracellular polymeric substances, glycoconjugates, confocal laser scanning microscopy

\section{INTRODUCTION}

Extracellular polymeric substances (EPS) represent, in terms of weight and volume, a major structural com-

\footnotetext{
Abbreviations: CLSM, confocal laser scanning microscopy; CY5, cyanine dye; EPS, extracellular polymeric substances; FITC, fluorescein isothiocyanate; ICBA, intensity-corrected binding area; LSD, least significant difference; TRITC, tetramethyl rhodamine isothiocyanate; UEA-I, Ulex euroaeus lectin $\mathrm{I}$.
}

ponent of interfacial microbial communities (Cooksey, 1992). EPS are responsible for the interaction of microorganisms with each other as well as with interfaces (Neu \& Marshall, 1990) and EPS act as a sorptive biofilm constituent (Flemming et al., 1996). Generally, EPS are understood to be extracellular polymers mainly composed of microbial polysaccharides. However, by definition, other extracellular polymeric substances may also be associated with biofilm systems, for example proteins, nucleic acids and polymeric lipophilic com- 
pounds (Neu, 1996; Neu \& Lawrence, 1999; Wingender et al., 1999). The EPS in complex environmental biofilm systems are difficult, if not impossible, to chemically characterize on the basis of isolating a single polymer species. Further, the state of the art carbohydrate analysis for polysaccharide characterization is suited only for the examination of purified polysaccharides. Usually, bacterial pure cultures have been grown in liquid media to produce a specific microbial polysaccharide. The polysaccharide was then isolated from the culture supernatant or the remaining cell pellet for subsequent chemical analysis. Only a few attempts have been made to examine true adhesive or biofilm polysaccharides (see Neu, 1994 for review). Despite this problem, several approaches to chemically quantify EPS constituents in biofilm systems have been reported (see review by Nielsen \& Jahn, 1999).

Labelled lectins have been successfully used in many microbial pure culture studies to probe for cell-surface structures. They were employed in transmission electron microscopy studies of the bacterial capsule (Vasse et al., 1994), cell surface localization of specific carbohydrates (Jones et al., 1986; Morioka et al., 1987), detection of slime in biofilms (Sanford et al., 1995) and characterization of adhesive surface appendages e.g. holdfasts (Merker \& Smit, 1988; Hood \& Schmidt, 1996). Fluorconjugated lectins have been used in flow cytometry studies to compare the cell surface chemistry versus the cell agglutination behaviour (Yagoda-Shagam et al., 1988). Most investigations using fluor-conjugated lectins were done using binding assays and subsequent epifluorescence microscopy. Thereby, the special features of the Caulobacter holdfast (Merker \& Smit, 1988; Ong et al., 1990), the adhesive capsule of Hyphomonas (Quintero \& Weiner, 1995) and microbial 'footprints' (Neu \& Marshall, 1991) were examined. Furthermore, lectins have been employed as an enzyme-linked lectinsorbent assay to quantify biofilm development (Thomas et al., 1997). Finally, there are the first reports on the application of lectins in complex environments e.g. marine habitats (Michael \& Smith, 1995) as well as freshwater systems (Neu \& Lawrence, 1997; Lawrence et al., 1998a; Neu, 2000) and multi-species biofilm communities (Wolfaardt et al., 1998). Thus lectins may represent a useful probe for in situ techniques to threedimensionally examine the distribution of glycoconjugates in fully hydrated environmental biofilm systems (Neu \& Lawrence, 1999).

For the evaluation of lectin-binding analysis, the structural complexity of microbial polysaccharides must be considered. The potential of carbohydrates to encode information in terms of saccharides is even larger than that of amino acids and nucleotides. The latter two compounds can only build one dimer whereas one type of monosaccharide can form 11 different disaccharides. Further, four monosaccharides, which is a common number in the repeating unit of polysaccharides, may form 35560 different disaccharides (Sharon \& Lis, 1989). This demonstrates the enormous variety of polysaccharides that may be expected from the diversity of microbial species that may colonize and form biofilms at environmental interfaces. In addition, it explains why specificity in nature is written in the form of saccharides. However, this may also indicate the possible difficulties and limitations in the applicability of lectin-binding analysis for the complex matrices common to environmental biofilm systems. The key interactions of lectins with carbohydrates are stereochemically via hydrogen bonds, metal coordination, and van der Waals and hydrophobic interactions (Liener et al., 1986; Weiss \& Drickamer, 1996; Elgavish \& Shaanan, 1997). Generally, lectins interact with their target through multiple binding sites, which increases affinity and specificity. These basic principles also apply to lectin interactions within complex interfacial microbial communities in the environment.

In this study lectin-binding analysis is described as a technique to probe for glycoconjugate distribution in environmental model biofilms grown with river water as the sole source of carbon and nutrients. The biofilms were stained with various fluor-conjugated lectins and three-dimensionally examined by confocal laser scanning microscopy (CLSM). The staining technique was critically assessed using several control experiments in order to refine lectin-binding analysis as an in situ tool in biofilm research.

\section{METHODS}

Biofilm culture and staining. Lotic biofilms were grown in rotating annular biofilm reactors as described in detail by $\mathrm{Neu}$ \& Lawrence (1997). The bioreactors contained polycarbonate slides which could be removed for microscopic examination of the biofilms. The bacteria in the biofilms were stained with nucleic acid specific SYTO 9 or SYTO 63 (Molecular Probes). Fluorescent lectins with fluorescein isothiocyanate (FITC) or tetramethyl rhodamine isothiocyanate (TRITC) labelling were purchased (Sigma). Cyanine (CY5) labelling was done using a commercial labelling kit according to the manufacturer's instructions (Research Organics). The lectins were employed alone or in combination for double and triple staining. In brief, the lectins were dissolved at $100 \mu \mathrm{g} \mathrm{ml}^{-1}$ in filter-sterilized $(0 \cdot 2 \mu \mathrm{m})$ river water. The slide pieces of about $1 \mathrm{~cm}^{2}$ carrying the biofilm were directly covered with $100 \mu \mathrm{l}$ lectin solution. The samples were then incubated in a humid chamber at room temperature $\left(22 \pm 2{ }^{\circ} \mathrm{C}\right)$ for various times to assess the time required to achieve complete staining. After determination of optimal staining time, the effect of lectin concentration $\left(5-100 \mu \mathrm{g} \mathrm{cm}^{-2}\right)$ was similarly determined. After staining, all the slide pieces were carefully rinsed with filtersterilized river water four times to remove unbound lectins. For each rinse the wash water was carefully added to the biofilm and drawn off with filter paper.

CLSM and image analysis. Examination of all stained and control materials was carried out using an MRC 1000 confocal laser scanning microscope (Bio-Rad) attached to a Microphot SA microscope (Nikon). For observation, the following waterimmersible lenses were used: $63 \times 0.9 \mathrm{NA}$ (Zeiss) and $40 \times 0.55$ NA (Nikon). Signals were recorded in the green channel (excitation $488 \mathrm{~nm}$, emission 522/32 nm), red channel (excitation $568 \mathrm{~nm}$, emission $605 / 32 \mathrm{~nm}$ ) and far-red channel (excitation $647 \mathrm{~nm}$, emission 680/32 nm). Image analyses were performed using NIH Image version 1.61 (http:// 
rsb.info.nih.gov/nih-image/). Additional information on CLSM and image analysis may be found in Lawrence et al. (1998b). Files were printed from Photoshop 5.5 (Adobe) using a UP-D8800 digital printer (SONY).

Experimental design, sampling and statistical analysis. A series of replicated experiments were carried out to assess the effects of incubation time, concentration, the nature of the fluorescent conjugate (FITC, TRITC or CY5), the order of addition of the lectins, interactions between lectins, the presence of inhibiting carbohydrates and the effect of the biofilm matrix. A series of CLSM images were taken at five random locations on all control and treatment slide pieces. Controls consisted of unstained slide pieces which were examined and used to determine the laser intensity, pinhole, gain and voltage settings of the CLSM at which no signal was detected. Settings were then adjusted using stained material and these levels held constant throughout the collection of experimental image series to provide a basis for comparison of treatment effects.

Statistical analyses were done by using a one way analysis of variance (ANOVA). Pair wise comparisons following a significant ANOVA were conducted using Fisher least significant difference (LSD) test. Differences were considered to be significant at $P \leqslant 0 \cdot 05$.

Quantitative estimation of lectin binding. Although it is complicated to determine the exact thickness of an optical section, our observations indicate that when imaging with a $40 \times 0.55 \mathrm{NA}$ water-immersible lens, the optical thin section is approximately $5 \mu \mathrm{m}$. Calculations of the theoretical thickness of an optical section taken with this lens indicate a thickness of $4 \mu \mathrm{m}$ (Xiao \& Kino, 1987). Therefore any single optical section in our calculation was assumed to be $5 \mu \mathrm{m}$ in thickness.

Image analysis was used to define the area of the biofilm binding a specific lectin. In addition, the mean grey value of the defined area was determined. These two parameters were used to quantify the area binding a specific lectin according to equation (1).

$\% I C B A=\frac{T A \times A G V \times 100}{255 \times 393216}$

$\%$ ICBA, intensity-corrected binding area; $T A$, thresholded area of lectin binding; $A G V$, average grey value within thresholded area; $255=$ grey value of saturated pixels $; 393216$ $=$ number of pixels in a full image $(768 \times 512)$.

\section{RESULTS}

\section{Effect of incubation time}

Experiments with a time scale from 0 to 30 min were carried out to determine the optimal incubation time for staining (Fig. 1). After $10 \mathrm{~min}$ a maximum binding area and intensity were found. From $20 \mathrm{~min}$ onwards the binding area declined to about one third of its maximum value. As a result, $20 \mathrm{~min}$ was chosen for all subsequent experiments.

\section{Effect of lectin concentration}

Experiments assessing the effect of lectin concentration indicated increasing fluorescence intensity with increasing lectin concentration (Fig. 2). Saturation was not

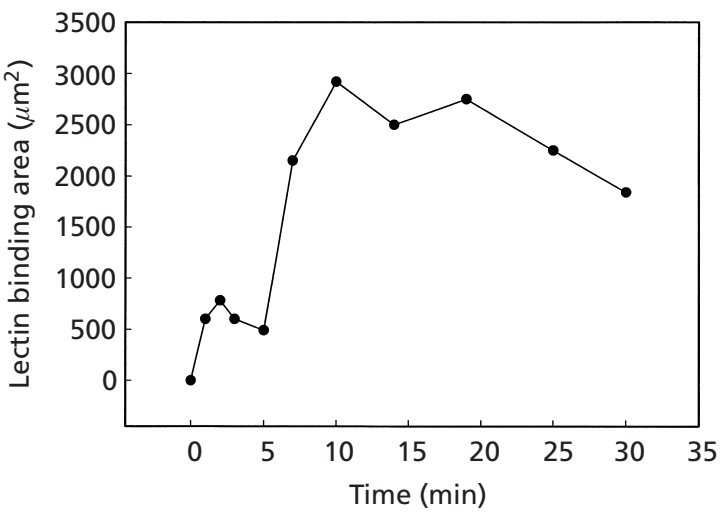

Fig. 1. Effect of incubation time on lectin binding.

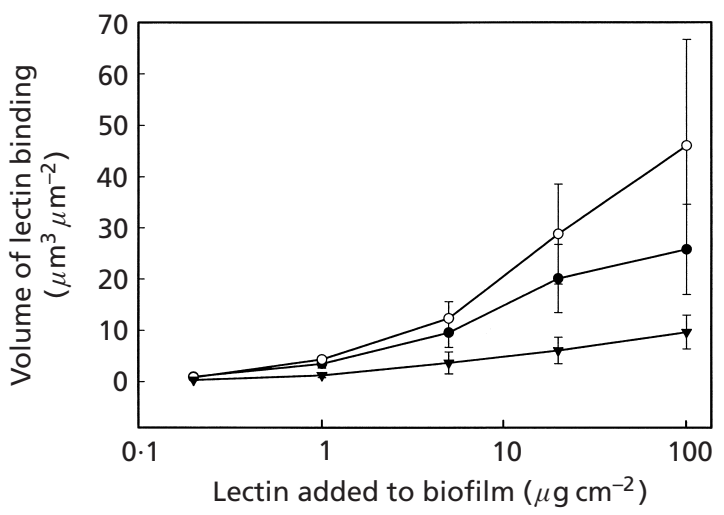

Fig. 2. Effect of lectin concentration on ICBA for the FITCconjugated lectins of Helix aspersa $(\bullet)$, Phaseolus vulgaris $(\mathrm{O})$ and Tri. vulgaris $(\boldsymbol{\nabla})$.

observed in the concentration range used for the three FITC-conjugated lectins and within standardized CLSM settings.

\section{Single, double and triple labelling}

Initial data clearly showed the potential of single-lectinbinding analysis to demonstrate glycoconjugate distribution in complex three-dimensional biofilm systems (Fig. 3a). The presence of two typical lectin-binding patterns (cell-surface associated and diffuse or cloudlike) are also evident in Fig. 3(b). Double labelling allowed the demonstration of each of the single glycoconjugates as well as binding of both glycoconjugates at the same location (Fig. 3c). Double lectin labelling could also be combined with nucleic acid staining to demonstrate the location of glycoconjugates relative to cell and microcolonies in the biofilm structure (Fig. $3 \mathrm{~d}$ ). It was also possible to carry out triple labelling with lectin combinations covering the FITC, TRITC and CY5 emission wavelengths (Fig. 3e,f). However, further evaluation of dual- and triple-labelling patterns indi- 

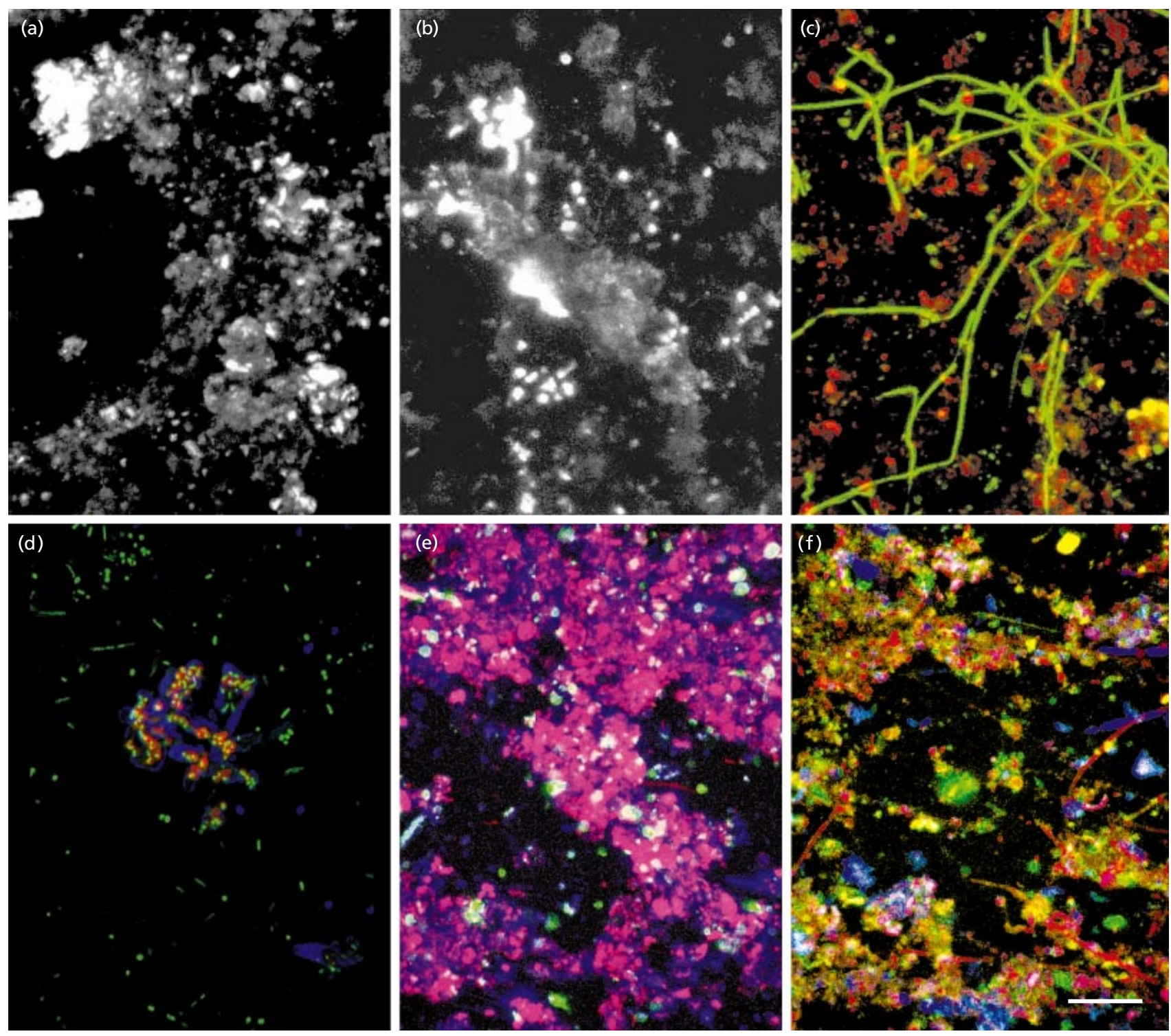

Fig. 3. Lotic biofilms showing binding pattern of a single lectin, multiple lectins and lectin-nucleic acid staining. (a) River biofilm with binding pattern of $C$. ensiformis-FITC lectin. (b) Single lectin stain (A. hypogaea-FITC), showing the typical cell-associated and diffuse or cloud-like binding patterns of lectins in biofilm matrices. (c) Double-lectin staining with $A$. hypogaea-FITC (green) and U. europaeus-TRITC (red). (d) Double-lectin staining with Tri. vulgaris-TRITC (red) and Tet. purpureas-CY5 (blue) combined with nucleic acid stain SYTO 9 (green). (e) Triple-lectin staining using L. polyphemus-FITC (green), U. europaeus-TRITC (red) and A. hypogaea-CY5 (blue). The double binding of two lectins resulted in either pink or bright blue colour overlay. (f) Triple-lectin staining using U. europaeus-FITC (green), Tri. vulgaris-TRITC (red) and A. hypogaea-CY5 (blue). At various locations the overlay of RGB colours identified the double binding of two lectins. Bar, $25 \mu \mathrm{m}$.

cated results that could not be explained by the selective nature of lectin binding. These effects were examined in the following experiments.

\section{Effect of fluor labelling on lectin binding}

The effect of FITC, TRITC and CY5 labelling on the binding of single lectins is shown in Fig. 4. Based on visual examination of the images, the lectin of Tetragonolobus purpureas showed a similar strong signal with all three labels (Fig. $4 \mathrm{a}-\mathrm{c})$. The Ulex europaeus lectin showed a relatively weak signal for FITC and stronger signals for TRITC and CY5 (Fig. 4d-f), whereas, the Arachis hypogaea lectin showed a localized intense binding of the FITC- and CY5-labelled lectin and a strong general binding of the TRITC-labelled lectin (Fig. 4g-i). The strong filamentous signals in the far-red channel are caused by the autofluorescence of phototrophic organisms (Fig. 4c, f, i).

The effect of FITC and TRITC lectin labelling was further tested in dual staining with U. europaeus lectin 

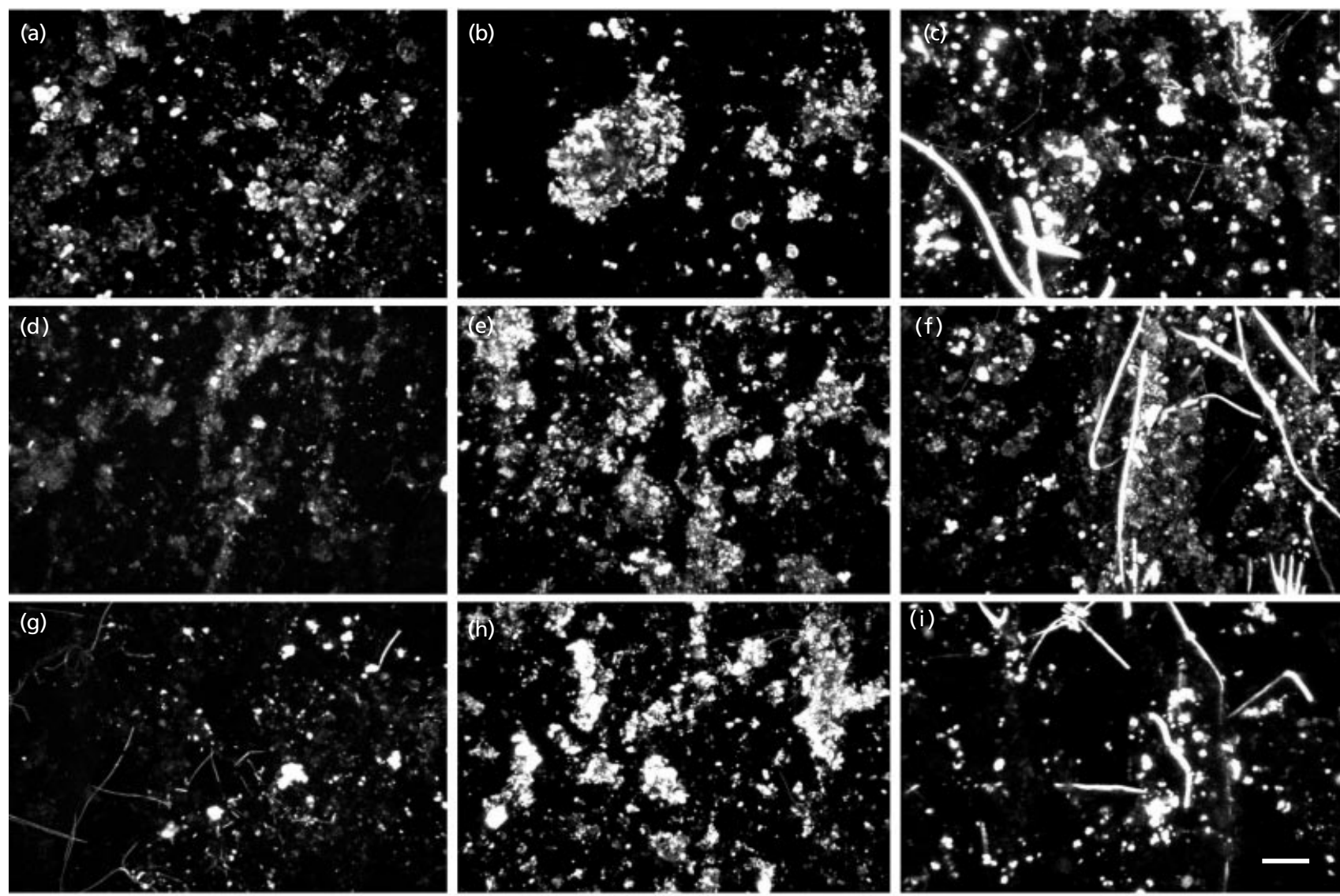

Fig. 4. Effect of fluor labelling (FITC, TRITC or CY5) on the binding of the lectins of $A$. hypogaea, Tet. purpureas and U. europaeus, demonstrated as a single-channel scan. (a) A. hypogaea-FITC, (b) A. hypogaea-TRITC, (c) A. hypogaea-CY5, (d) Tet. purpureas-FITC, (e) Tet. purpureas-TRITC, (f) Tet. purpureas-CY5, (g) U. europaeus-FITC, (h) U. europaeus-TRITC, (i) U. europaeus-CY5. Bar, $25 \mu \mathrm{m}$.
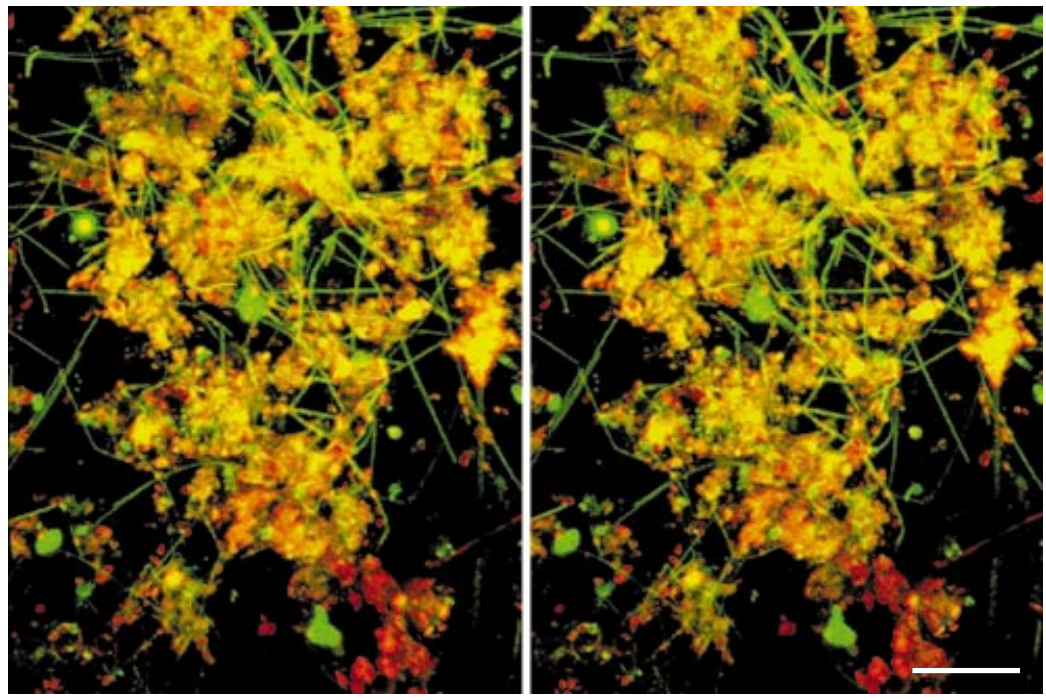

Fig. 5. Effect of conjugated fluor if the same lectin is used for double staining. The stereo image shows in green the $U$. europaeus-FITC single binding, in red the $U$. europaeus-TRITC single binding and in yellow the binding of both $U$. europaeus lectins to the same location. Bar, $25 \mu \mathrm{m}$.

(UEA-I). The stereo image in Fig. 5 shows in green the FITC-UEA-I single binding, in red the TRITC-UEA-I single binding and in yellow the binding of both UEA-Is to the same location. This pattern indicated that there was differential binding of UEA-I and that this was related to the nature of the conjugated fluorescent label. 

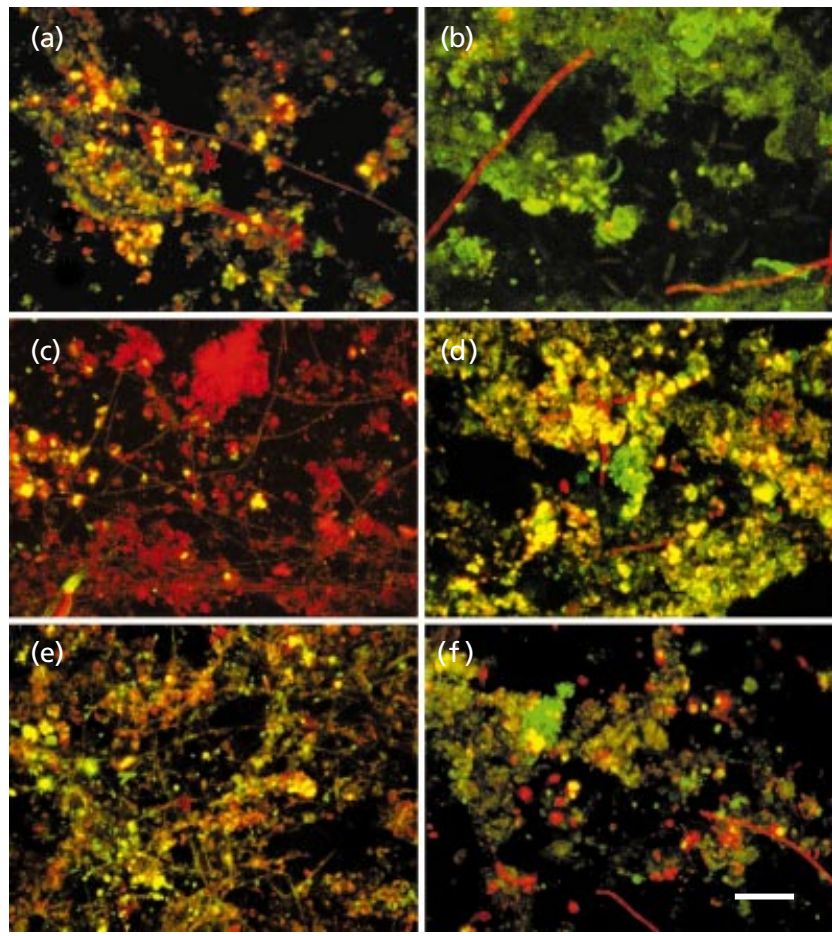

Fig. 6. Double-lectin staining showing the effect of order of addition and fluor conjugated to the lectin. (a) Tet. purpureas-FITC first, $U$. europeaus-TRITC second; (b) Tet. purpureas-TRITC first, $U$. europeaus-FITC second; (c) $U$. europeaus-FITC first, Tet. purpureas-TRITC second; (d) $U$. europeaus-TRITC first, Tet. purpureas-FITC second; (e) $A$ hypogaea-FITC first, Tet. purpureas-TRITC second; (f) $A$. hypogaea-TRITC first, Tet. purpureas-FITC second. Bar, $25 \mu \mathrm{m}$.

Similar results were obtained when dual labelling was carried out using other FITC- and TRITC-conjugated lectins.

\section{Effect of fluorochrome and order of addition on lectin binding}

Three different lectins (Tet. purpureas, U. europeaus and A. hypogaea) were employed to test the effect of variation in order of addition and the effect of fluor labelling (FITC, TRITC) on binding. When Tet. purpureas-FITC was added first and U. europeausTRITC second, the binding of each is about equal with red, green and yellow areas with a shift into the red (Fig. 6a). If Tet. purpureas-TRITC was added first and $U$. europeaus-FITC second, the merged images were dominated by the green FITC signal (Fig. 6b). Reversal of the order of addition of the lectins, with $U$. europeaus-FITC added first and Tet. purpureasTRITC second, revealed a merged image which was dominated by the red TRITC signal. However, in some areas the yellow signal indicative of double staining with FITC and TRITC can be seen (Fig. 6c). When $U$. europeaus-TRITC was added first and Tet. purpureasFITC second (Fig. 6d), the binding of each is also about
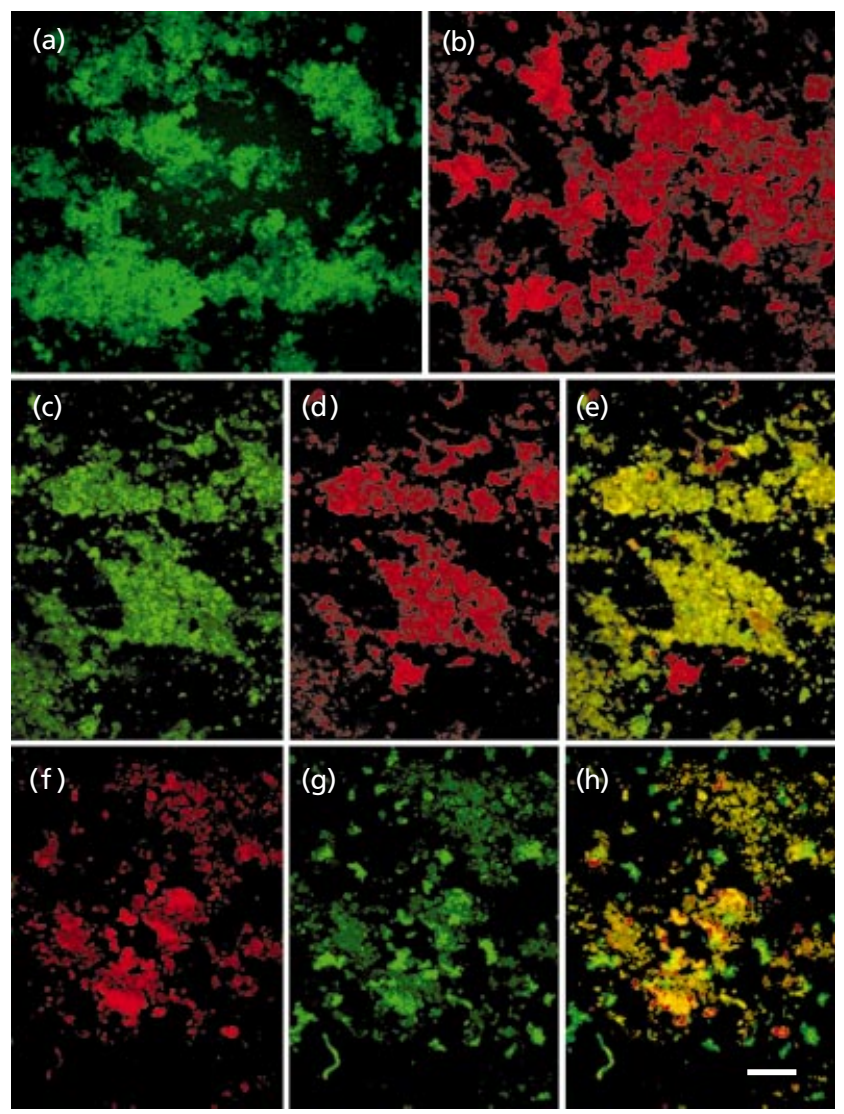

Fig. 7. Effect of interaction between two different lectins both having a specificity for fucose. (a) $U$. europaeus-FITC binding pattern, (b) Tet. purpureas-TRITC binding pattern, (c-e) green and red dual-channel images and the merged image when $U$. europaeus-FITC was added first and Tet. purpureas-TRITC second, $(f-h)$ green and red dual-channel images as well as the merged image when Tet. purpureas-TRITC was added first and $U$. europaeus-FITC second. Bar, $25 \mu \mathrm{m}$.

equal with red, green and yellow areas however with a shift into the green. This is similar to Fig. 6(a) with the lectin order reversed. If A. hypogaea-FITC or-TRITC was added first, the merged images showed a balance of the green FITC signal, the red TRITC signal and the yellow signal (double staining) (Fig. 6e, f).

In initial experiments, we examined the effect of order of addition on the binding pattern of double-lectin staining using the two fucose-specific lectins Tet. purpureasTRITC and UEA-I-FITC. In Fig. 7 ( $a, b)$, the binding pattern of the two lectins is shown when added separately to the biofilm. In Fig. 7 (c-e) the green and red dual-channel images as well as the merged images are presented when UEA-I-FITC was added first followed by Tet. purpureas-TRITC. In Fig. $7(\mathrm{f}-\mathrm{h})$ the reverse staining with Tet. purpureas-TRITC added first and UEA-I-FITC added second are shown as single and merged images. The two merged images show that order of addition influenced the binding pattern of the lectins. Although both lectins have an affinity for fucose- 
Table 1. The effect of TRITC-labelled lectins on FITC-labelled lectins depending on the order of addition in a series of two-lectin combinations

\begin{tabular}{|c|c|c|c|c|}
\hline \multirow[t]{2}{*}{ First lectin } & \multirow[t]{2}{*}{ Second lectin } & \multicolumn{2}{|c|}{ FITC channel } & \multirow[t]{2}{*}{ Observation } \\
\hline & & $\%$ ICBA & Significance* & \\
\hline \multicolumn{5}{|l|}{ Arachis-FITC } \\
\hline Arachis-FITC & Arachis-TRITC & $0 \cdot 09$ & $\mathrm{ab}$ & Arachis-FITC is not affected \\
\hline Arachis-FITC & Tet.-TRITC & $0 \cdot 10$ & $a b$ & by any other lectin whether it \\
\hline Arachis-FITC & Ulex-TRITC & $0 \cdot 20$ & $\mathrm{bc}$ & is added first or second \\
\hline Arachis-TRITC & Arachis-FITC & $0 \cdot 08$ & $\mathrm{ab}$ & \\
\hline Tet.-TRITC & Arachis-FITC & $0 \cdot 05$ & $\mathrm{a}$ & \\
\hline Ulex-TRITC & Arachis-FITC & $0 \cdot 04$ & a & \\
\hline Arachis-FITC & Control & $0 \cdot 07$ & $a b$ & \\
\hline \multicolumn{5}{|l|}{ Tet.-FITC } \\
\hline Tet.-FITC & Arachis-TRITC & $0 \cdot 09$ & $a b$ & The fluorescence of Tet.-FITC \\
\hline Tet.-FITC & Tet.-TRITC & $0 \cdot 07$ & $a b$ & is decreased by all the other \\
\hline Tet.-FITC & Ulex-TRITC & $0 \cdot 03$ & $\mathrm{a}$ & lectins whether they are \\
\hline Arachis-TRITC & Tet.-FITC & $0 \cdot 13$ & bc & added first or second \\
\hline Tet.-TRITC & Tet.-FITC & $0 \cdot 06$ & a† & \\
\hline Ulex-TRITC & Tet.-FITC & $0 \cdot 08$ & $a b$ & \\
\hline Tet.-FITC & Control & $0 \cdot 25$ & $\mathrm{~d}$ & \\
\hline \multicolumn{5}{|l|}{ Ulex-FITC } \\
\hline Ulex-FITC & Arachis-TRITC & $0 \cdot 02$ & a† & The fluorescence of \\
\hline Ulex-FITC & Tet.-TRITC & $0 \cdot 02$ & a† & Ulex-FITC decreased by \\
\hline Ulex-FITC & Ulex-TRITC & $0 \cdot 10$ & $\mathrm{~b}$ & Arachis- and Tet.-TRITC \\
\hline Arachis-TRITC & Ulex-FITC & $0 \cdot 04$ & a† & when they are added second \\
\hline Tet.-TRITC & Ulex-FITC & $0 \cdot 29$ & c & and by Arachis- and \\
\hline Ulex-TRITC & Ulex-FITC & $0 \cdot 03$ & a† & Ulex-TRIC when they are \\
\hline Ulex-FITC & Control & $0 \cdot 09$ & $\mathrm{ab}$ & $\begin{array}{l}\text { added first. Tet.-TRITC } \\
\text { increases the fluorescence of } \\
\text { Ulex-FITC when it is added } \\
\text { first }\end{array}$ \\
\hline
\end{tabular}

$* P \leqslant 0 \cdot 05$ unless indicated $\dagger$, where $P \leqslant 0 \cdot 01$. Values followed by the same letters or combination of letters are not significantly different.

containing glycoconjugates, the Tet. purpureas-TRITC lectin has a 10-1000-fold higher affinity according to the suppliers' data sheet and substantially alters the binding pattern of UEA-I-FITC.

To quantitatively determine the effect of lectin interactions during staining, all combinations of Tet. purpureas, U. europaeus and A. hypogaea lectins conjugated with either FITC or TRITC were prepared and the binding area determined. These results were compared with those obtained for each lectin applied individually. A statistical analysis of the results of these experiments is presented in Tables 1 and 2. The results indicated that Arachis FITC was not significantly influenced by any of the other TRITC-conjugated lectins; however, ArachisTRITC was inhibited by the presence of other lectins regardless of order of addition. Similarly, Tetragonolobus-FITC was inhibited by the presence of TRITC-conjugated lectins regardless of order of addition. Ulex-FITC was inhibited by Arachis- and Tetragonolobus-TRITC when added first; it was also inhibited by the presence of Arachis- and Ulex-TRITC when it was added second. In contrast, the Ulex-FITC binding was enhanced by the presence of Tetragonolobus-TRITC lectin. The presence of other lectins had a significant inhibitory effect on the binding of Ulex-TRITC in all instances. Based on these observations, the relative binding affinities of the respective lectin fluor conjugates would be Arachis-FITC, UlexFITC, Tetragonolobus-TRITC, Arachis-TRITC, Ulex-TRITC, Tetragonolobus-FITC. The results summarized in Tables 1 and 2 and the relative affinities also indicate that binding was significantly influenced by the nature of fluorescent conjugate and the order of addition.

\section{Effect of carbohydrate inhibition on lectin-binding affinities}

According to the manufacturer's data sheet, UEA-I is specific to L-fucose only. Therefore, this lectin was selected to test the effect of increasing fucose concen- 
Table 2. The effect of FITC-labelled lectins on TRITC-labelled lectins depending on the order of addition in a series of two-lectin combinations

\begin{tabular}{|c|c|c|c|c|}
\hline \multirow[t]{2}{*}{ First lectin } & \multirow[t]{2}{*}{ Second lectin } & \multicolumn{2}{|c|}{ TRITC channel } & \multirow[t]{2}{*}{ Observation } \\
\hline & & $\%$ ICBA & Significance* & \\
\hline \multicolumn{5}{|l|}{ Arachis-TRITC } \\
\hline Arachis-TRITC & Arachis-FITC & $0 \cdot 21$ & $\mathrm{bc}$ & \multirow{7}{*}{$\begin{array}{l}\text { The fluorescence of } \\
\text { Arachis-TRITC is decreased } \\
\text { by all the other FITC- } \\
\text { labelled lectins whether they } \\
\text { are added first or second }\end{array}$} \\
\hline Arachis-TRITC & Tet.-FITC & $0 \cdot 17$ & $a b$ & \\
\hline Arachis-TRITC & Ulex-FITC & $0 \cdot 17$ & $a b$ & \\
\hline Arachis-FITC & Arachis-TRITC & $0 \cdot 29$ & $\mathrm{c}$ & \\
\hline Tet.-FITC & Arachis-TRITC & $0 \cdot 10$ & $\mathrm{a}$ & \\
\hline Ulex-FITC & Arachis-TRITC & $0 \cdot 13$ & $\mathrm{a}$ & \\
\hline Arachis-TRITC & Control & $0 \cdot 38$ & $\mathrm{~d}$ & \\
\hline \multicolumn{5}{|l|}{ Tet.-TRITC } \\
\hline Tet.-TRITC & Arachis-FITC & $0 \cdot 11$ & a† & \multirow{7}{*}{$\begin{array}{l}\text { The fluorescence of } \\
\text { Tet.-TRITC is decreased by } \\
\text { adding Arachis-FITC and } \\
\text { Tet.-FITC second and by } \\
\text { adding Tet.-FITC first }\end{array}$} \\
\hline Tet.-TRITC & Tet.-FITC & $0 \cdot 09$ & $\mathrm{a}$ & \\
\hline Tet.-TRITC & Ulex-FITC & $0 \cdot 28$ & bc & \\
\hline Arachis-FITC & Tet.-TRITC & $0 \cdot 21$ & $\mathrm{~b}$ & \\
\hline Tet.-FITC & Tet.-TRITC & $0 \cdot 10$ & $\mathrm{a}$ & \\
\hline Ulex-FITC & Tet.-TRITC & $0 \cdot 15$ & $a b$ & \\
\hline Tet.-TRITC & Control & $0 \cdot 20$ & $\mathrm{~b}$ & \\
\hline \multicolumn{5}{|l|}{ Ulex-TRITC } \\
\hline Ulex-TRITC & Arachis-FITC & $0 \cdot 14$ & $\mathrm{a}$ & \multirow{7}{*}{$\begin{array}{l}\text { The fluorescence of } \\
\text { Ulex-TRITC is decreased by } \\
\text { all the other FITC-labelled } \\
\text { lectins whether they are } \\
\text { added first or second }\end{array}$} \\
\hline Ulex-TRITC & Tet.-FITC & $0 \cdot 12$ & a & \\
\hline Ulex-TRITC & Ulex-FITC & $0 \cdot 13$ & $\mathrm{a}$ & \\
\hline Arachis-FITC & Ulex-TRITC & $0 \cdot 20$ & $\mathrm{a}$ & \\
\hline Tet.-FITC & Ulex-TRITC & $0 \cdot 14$ & $\mathrm{a}$ & \\
\hline Ulex-FITC & Ulex-TRITC & $0 \cdot 36$ & $\mathrm{~b}$ & \\
\hline Ulex-TRITC & Control & $0 \cdot 58$ & c & \\
\hline
\end{tabular}

$* P \leqslant 0 \cdot 05$ unless indicated + , where $P \leqslant 0 \cdot 01$. Values followed by the same letters or combination of letters are not significantly different.
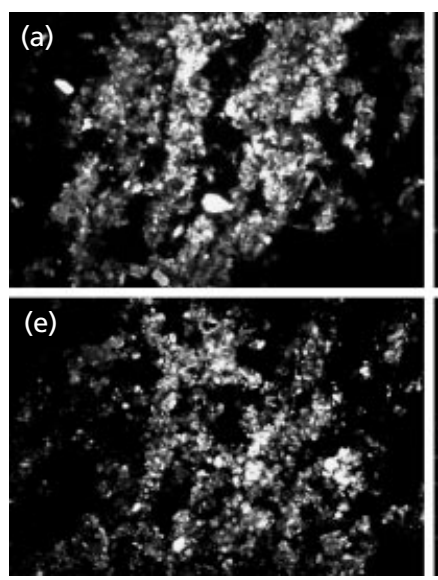
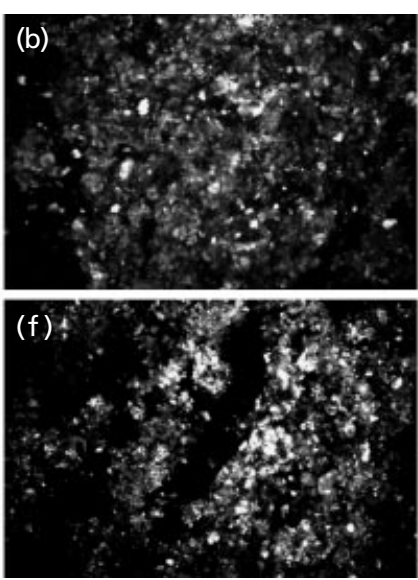
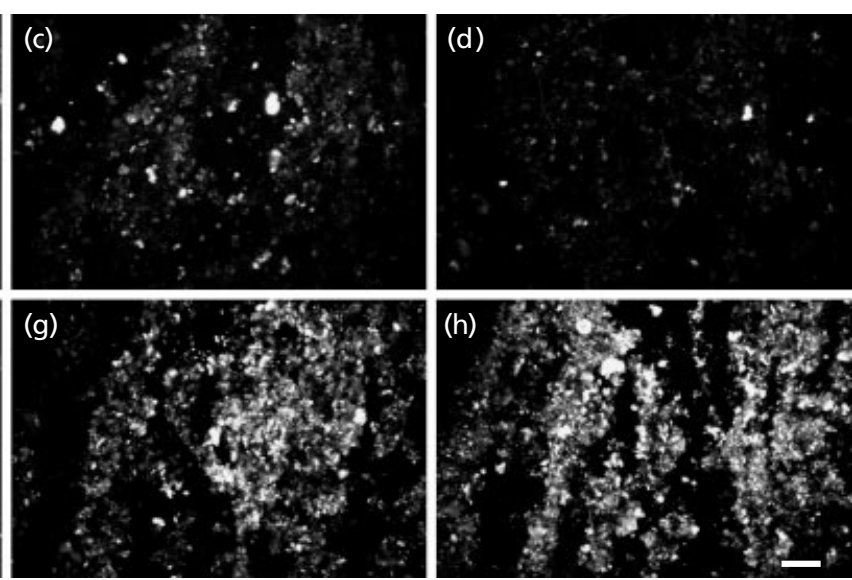

Fig. 8. Carbohydrate-inhibition experiment with $U$. europaeus (increasing fucose concentration from left to right). (a-d) Series with $U$. europaeus FITC lectin, (e-h) series with $U$. europaeus TRITC lectin. Bar, $25 \mu \mathrm{m}$.

trations on the lectin binding to the river biofilm samples. This test was performed with the FITC- and TRITC-labelled UEA-I. The result is shown in Fig. 8.
Although the FITC-conjugated Ulex lectin was inhibited by increasing fucose concentration $(0 \cdot 01-1 \mathrm{M})$, the TRITC series showed no effect. 
Table 3. Concentrations of carbohydrates used for lectin-inhibition experiments

\begin{tabular}{|lcc|}
\hline Carbohydrate & \multicolumn{2}{c|}{ Concn $\left(\mathbf{m g ~ m l}^{-\mathbf{1}}\right)$} \\
\cline { 2 - 3 } & $\mathbf{1 9 9 7}$ & $\mathbf{1 9 9 8}$ \\
\hline D(-)-Arabinose & 340 & 238 \\
D (-)-Fructose & 376 & - \\
L(-)-Fucose & 376 & 250 \\
D(+)-Galactose & 262 & 147 \\
D(+)-Glucose & 453 & 333 \\
D-Glucuronic acid & 267 & 139 \\
$\alpha$-Lactose & 270 & - \\
D(+)-Mannose & 282 & 313 \\
Melibiose & 325 & - \\
Methyl $\alpha$-D- & 105 & - \\
mannopyranoside & & \\
D(+)-Raffinose & 327 & - \\
L-Rhamnose & 284 & 200 \\
Sucrose & 442 & - \\
\hline
\end{tabular}

Based on the preliminary studies with $U$. europaeus lectin, we established a screening protocol using carbohydrate concentrations in the range of $1 \mathrm{M}$ (Table 3) to assess the influence on the percentage of ICBA. The selection of carbohydrates was based on those typically used to assess inhibition of blood agglutination and those reported in the literature to be components of bacterial EPS. Results of the inhibition study are summarized in Table 4. The ANOVA (LSD) indicated that as observed for Ulex lectin binding in the preliminary study, the carbohydrate inhibition was significantly dependent upon the nature of the fluorescent conjugate (FITC, TRITC). For example, the binding of FITC- and TRITC-conjugated Tetragonolobus lectins were either inhibited, enhanced or unaffected by the same sugars. It is also apparent that only the FITC-conjugated Tetragonolobus and Ulex lectins were inhibited by their specific carbohydrate fucose. Similar behaviour is evident for the other lectin carbohydrate combinations screened in these analyses.

Table 5 summarizes the effect of seven common bacterial exopolymer carbohydrates on the binding of nine different FITC-conjugated lectins. Observations indicated that the presence of the carbohydrates resulted in either inhibition, enhancement or no significant effect on the binding of the lectins relative to the control values for the same lectin and biofilm materials. It is apparent that both the Tetragonolobus and Ulex lectins, which are reported to have a high specificity, are inhibited in the biofilm matrix by a wider range of carbohydrates than initially predicted, while Lens and Wisteria lectins may be useful as probes with higher specificity. The lectins derived from Canavalia ensiformis, Triticum vulgaris and Limulus polyphemus all showed inhibition of binding by the wider range of carbohydrates screened, suggesting a very broad affinity for glycoconjugates in the biofilm matrix.

\section{Effect of biofilm matrix}

Biofilms were produced using river waters in 1997 and 1998 to repeat experiments evaluating the effects of carbohydrate inhibition on lectin binding in the matrix. In each year the biofilms were different in terms of age, architecture and presence of specific microcolony types, and thus represented different biofilm matrices for lectin analyses. Table 6 summarizes the effect of variation in biofilm matrix on the nature of carbohydrate inhibition. Changes in the inhibition patterns year to year, relative to control biofilm materials, probably reflect changes in the EPS chemistry of the biofilm. For example, in the 1997 data, application of mannose inhibited binding of Arachis and Ulex lectins; in contrast, in 1998 mannose applied resulted in a substantial enhancement of binding by these same lectins.

\section{DISCUSSION}

\section{Investigations using lectins}

Lectins have been used as probes in a few studies of environmental biofilm systems (Michael \& Smith, 1995; Neu \& Lawrence, 1997; Wolfaardt et al., 1998; Neu, 2000). It has been suggested that lectins could be applied as a specific probe at the polymer level similar to specific rRNA targeted probes at the cellular level (Neu, 2000). These studies indicated the utility of lectin-binding analysis; nevertheless, questions remain regarding the identity of the binding sites, the influence of fluorescent conjugates on the behaviour of the lectin and interactions between lectins in multiple-lectin staining.

\section{Quantitative analyses of lectin binding}

Assessment of the time for complete lectin binding to occur is essential to a practical reproducible assay. The results of our study indicated that an interval of $20 \mathrm{~min}$ was optimal for staining of complex lotic river biofilm materials. Previous studies (Merker \& Smit, 1988; Michael \& Smith, 1995; Hood \& Schmidt, 1996) also used 20 min, whereas Quintero \& Weiner (1995) used a $30 \mathrm{~min}$ incubation. Thus the incubation time for the essential assay is well established. The influence of lectin concentration is also a methodological consideration. In this study we were unable to find a saturating concentration for any lectin tested. This was in part due to the lack of dynamic range of the CLSM photomultipliers; once the photomultiplier is saturated no further effect of increasing lectin binding can be detected. However, by readjusting the gain, pinhole and laser intensity it was possible to obtain an image with a normal distribution of pixel intensity $(0-255)$ regardless of the lectin concentration added. Therefore we selected a standard concentration of lectin for the experiments.

Usually, two different types of signals are obtained in lectin-binding analyses of biofilms. Fluor-conjugated lectins stain cell surface carbohydrate features of prokaryotes and eukaryotes thereby giving a signal which defines the outline of the cell (Fig. 3b, c). In addition, lectins stain excreted and released carbohydrates present 
Table 4. Results of the 1997 carbohydrate-inhibition experiments showing the effect of fluor conjugation on sugar inhibition

i, Inhibited; e, enhanced; ns, not significantly different.

\begin{tabular}{|c|c|c|c|c|c|c|}
\hline \multirow[t]{2}{*}{ Carbohydrate } & \multicolumn{2}{|c|}{ FITC } & \multicolumn{2}{|c|}{ TRITC } & \multicolumn{2}{|c|}{ CY5 } \\
\hline & $P=0 \cdot 05$ & $\begin{array}{c}\% \text { of } \\
\text { control }\end{array}$ & $P=0 \cdot 0$ & $\begin{array}{c}\% \text { of } \\
\text { control }\end{array}$ & $P=0 \cdot 05$ & $\begin{array}{c}\% \text { of } \\
\text { control }\end{array}$ \\
\hline & \multicolumn{6}{|c|}{ Arachis hypogaea } \\
\hline & \multicolumn{2}{|c|}{$\mathrm{LSD}=11$} & \multicolumn{2}{|c|}{$\mathrm{LSD}=28$} & \multicolumn{2}{|c|}{$\mathrm{LSD}=30$} \\
\hline $\mathrm{D}(-)$-Arabinose & i & 87 & i & 70 & ns & 108 \\
\hline $\mathrm{D}(-)$-Fructose & $\mathrm{i}$ & 45 & $\mathrm{i}$ & 55 & ns & 85 \\
\hline $\mathrm{L}(-)$-Fucose & $\mathrm{i}$ & 21 & $\mathrm{i}$ & 73 & $\mathrm{i}$ & 45 \\
\hline $\mathrm{D}(+)$-Galactose & $\mathrm{i}$ & 60 & $\mathrm{i}$ & 68 & $\mathrm{e}$ & 161 \\
\hline $\mathrm{D}(+)$-Glucose & $\mathrm{i}$ & 85 & ns & 76 & ns & 74 \\
\hline D-Glucuronic acid & $\mathrm{e}$ & 151 & $\mathrm{i}$ & 45 & ns & 94 \\
\hline$\alpha$-Lactose & $\mathrm{e}$ & 121 & $\mathrm{i}$ & 54 & ns & 125 \\
\hline $\mathrm{D}(+)$-Mannose & $\mathrm{e}$ & 154 & ns & 87 & $\mathrm{i}$ & 63 \\
\hline Melibiose & ns & 102 & $\mathrm{i}$ & 60 & ns & 104 \\
\hline $\begin{array}{l}\text { Methyl } \alpha \text {-D- } \\
\text { mannopyranoside }\end{array}$ & $\mathrm{i}$ & 88 & ns & 119 & $\mathrm{e}$ & 193 \\
\hline $\mathrm{D}(+)$-Raffinose & $\mathrm{i}$ & 41 & ns & 84 & ns & 132 \\
\hline $\mathrm{L}(-)$-Rhamnose & $\mathrm{i}$ & 56 & $\mathrm{i}$ & 66 & ns & 76 \\
\hline \multirow[t]{3}{*}{ Sucrose } & $\mathrm{i}$ & 60 & ns & 113 & ns & 77 \\
\hline & \multicolumn{6}{|c|}{ Tet. purpureas } \\
\hline & \multicolumn{2}{|c|}{$\mathrm{LSD}=26$} & \multicolumn{2}{|c|}{$\mathrm{LSD}=10$} & \multicolumn{2}{|c|}{$\mathrm{LSD}=49$} \\
\hline $\mathrm{D}(-)$-Arabinose & $\mathrm{i}$ & 39 & $\mathrm{i}$ & 20 & ns & 93 \\
\hline $\mathrm{D}(-)$-Fructose & ns & 86 & $\mathrm{i}$ & 23 & ns & 116 \\
\hline $\mathrm{L}(-)$-Fucose & $\mathrm{i}$ & 33 & e & 143 & ns & 71 \\
\hline $\mathrm{D}(+)$-Galactose & ns & 125 & $\mathrm{i}$ & 38 & ns & 91 \\
\hline $\mathrm{D}(+)$-Glucose & $\mathrm{i}$ & 42 & $\mathrm{e}$ & 236 & ns & 95 \\
\hline D-Glucuronic acid & ns & 105 & $\mathrm{i}$ & 49 & $\mathrm{i}$ & 36 \\
\hline$\alpha$-Lactose & ns & 105 & $\mathrm{i}$ & 25 & ns & 89 \\
\hline $\mathrm{D}(+)$-Mannose & ns & 77 & $\mathrm{i}$ & 33 & ns & 132 \\
\hline Melibiose & $\mathrm{e}$ & 139 & $\mathrm{i}$ & 80 & ns & 107 \\
\hline $\begin{array}{l}\text { Methyl } \alpha \text {-D- } \\
\text { mannopyranoside }\end{array}$ & ns & 104 & $\mathrm{i}$ & 18 & ns & 82 \\
\hline $\mathrm{D}(+)$-Raffinose & ns & 124 & $\mathrm{i}$ & 73 & ns & 112 \\
\hline $\mathrm{L}(-)$-Rhamnose & $\mathrm{i}$ & 67 & $\mathrm{i}$ & 45 & ns & 143 \\
\hline \multirow[t]{3}{*}{ Sucrose } & ns & 90 & $\mathrm{i}$ & 87 & ns & 103 \\
\hline & \multicolumn{6}{|c|}{ Ulex europaeus } \\
\hline & \multicolumn{2}{|c|}{ LSD $=8$ or $* 13$} & \multicolumn{2}{|c|}{$\mathrm{LSD}=12$ or $* 43$} & \multicolumn{2}{|c|}{$\mathrm{LSD}=30$} \\
\hline $\mathrm{D}(-)$-Arabinose & $\mathrm{i}$ & 13 & i & 9 & $\mathrm{i}$ & 41 \\
\hline $\mathrm{D}(-)$-Fructose & $\mathrm{i}$ & 17 & ns & i & ns & 76 \\
\hline $\mathrm{L}(-)$-Fucose & $* \mathrm{i}$ & 30 & "ns & 110 & $\mathrm{i}$ & 53 \\
\hline $\mathrm{D}(+)$-Galactose & $* \mathrm{e}$ & 119 & *ns & 74 & ns & 95 \\
\hline $\mathrm{D}(+)$-Glucose & $* \mathrm{e}$ & 131 & $* \mathrm{e}$ & 162 & ns & 81 \\
\hline D-Glucuronic acid & $\mathrm{i}$ & 14 & $\mathrm{i}$ & 46 & $\mathrm{i}$ & 46 \\
\hline$\alpha$-Lactose & $\mathrm{e}$ & 140 & $\mathrm{e}$ & 128 & ns & 99 \\
\hline $\mathrm{D}(+)$-Mannose & $* \mathrm{e}$ & 124 & *ns & 88 & $\mathrm{i}$ & 54 \\
\hline Melibiose & $\mathrm{i}$ & 33 & ns & 89 & ns & 81 \\
\hline $\begin{array}{l}\text { Methyl } \alpha \text {-D- } \\
\text { mannopyranoside }\end{array}$ & $\mathrm{i}$ & 83 & $\mathrm{e}$ & 172 & $\mathrm{i}$ & 52 \\
\hline $\mathrm{D}(+)$-Raffinose & $\mathrm{i}$ & 24 & e & 135 & ns & 106 \\
\hline L-Rhamnose & $\mathrm{e}$ & 115 & $\mathrm{e}$ & 146 & ns & 94 \\
\hline Sucrose & $* \mathrm{e}$ & 152 & *ns & 114 & ns & 79 \\
\hline
\end{tabular}

*Indicates the higher LSD. 
Table 5. Results of carbohydrate-inhibition experiments: inhibition of FITC-conjugated lectins by carbohydrates found in bacterial exopolysaccharides

i, Inhibited; e, enhanced; ns, not significantly different.

\begin{tabular}{|c|c|c|c|c|c|c|c|c|c|c|c|c|c|c|c|c|c|c|}
\hline \multirow[t]{3}{*}{ Carbohydrate } & \multicolumn{2}{|c|}{ C. ensiformis } & \multicolumn{2}{|c|}{ Lens culinaris } & \multicolumn{2}{|c|}{ Tet. purpureas } & \multicolumn{2}{|c|}{ Tri. vulgaris } & \multirow{2}{*}{\multicolumn{2}{|c|}{$\begin{array}{l}\text { Wisteria } \\
\text { floribunda }\end{array}$}} & \multirow{2}{*}{\multicolumn{2}{|c|}{$\begin{array}{l}\text { Limulus } \\
\text { polyphemus }\end{array}$}} & \multicolumn{2}{|c|}{ U. europaeus } & \multicolumn{2}{|c|}{ Glycine max } & \multicolumn{2}{|c|}{ A. hypogaea } \\
\hline & \multirow{2}{*}{$P=0.05$} & \multirow{2}{*}{$\begin{array}{c}\% \text { of } \\
\text { control }\end{array}$} & \multirow{2}{*}{$P=0.05$} & \multirow{2}{*}{$\begin{array}{c}\% \text { of } \\
\text { control }\end{array}$} & \multirow{2}{*}{$P=0.05$} & \multirow{2}{*}{$\begin{array}{c}\% \text { of } \\
\text { control }\end{array}$} & \multirow{2}{*}{$P=0.05$} & \multirow{2}{*}{$\begin{array}{c}\% \text { of } \\
\text { control }\end{array}$} & & & & & \multirow{2}{*}{$P=0.05$} & \multirow{2}{*}{$\begin{array}{c}\% \text { of } \\
\text { control }\end{array}$} & \multirow{2}{*}{$P=0.05$} & \multirow{2}{*}{$\begin{array}{l}\% \text { of } \\
\text { control }\end{array}$} & \multirow{2}{*}{$P=0.05$} & \multirow{2}{*}{$\begin{array}{c}\% \text { of } \\
\text { control }\end{array}$} \\
\hline & & & & & & & & & $P=0.05$ & $\begin{array}{l}\% \text { of } \\
\text { control }\end{array}$ & $P=0.05$ & $\begin{array}{c}\% \text { of } \\
\text { control }\end{array}$ & & & & & & \\
\hline & \multicolumn{2}{|c|}{$\mathrm{LSD}=27$} & \multicolumn{2}{|c|}{$\mathrm{LSD}=37$} & \multicolumn{2}{|c|}{$\mathrm{LSD}=29$} & \multicolumn{2}{|c|}{$\mathrm{LSD}=26$} & \multicolumn{2}{|c|}{$\mathrm{LSD}=34$} & \multicolumn{2}{|c|}{$\mathrm{LSD}=38$} & \multicolumn{2}{|c|}{$\mathrm{LSD}=17$} & \multicolumn{2}{|c|}{$\mathrm{LSD}=34$} & \multicolumn{2}{|c|}{$\mathrm{LSD}=26$} \\
\hline $\mathrm{D}(-)$-Arabinose & i & 15 & ns & 114 & i & 28 & $\mathrm{i}$ & 32 & ns & 70 & i & 25 & i & 44 & i & 56 & i & 61 \\
\hline $\mathrm{D}(+)$-Glucose & $\mathrm{i}$ & 22 & $\mathrm{i}$ & 40 & $\mathrm{i}$ & 40 & $\mathrm{i}$ & 56 & ns & 87 & $\mathrm{i}$ & 59 & $\mathrm{i}$ & 29 & ns & 82 & $\mathrm{i}$ & 29 \\
\hline $\mathrm{L}(-)$-Fucose & $\mathrm{i}$ & 19 & ns & 93 & $\mathrm{i}$ & 23 & $\mathrm{i}$ & 34 & $\mathrm{~ns}$ & 88 & $\mathrm{i}$ & 10 & $\mathrm{i}$ & 21 & i & 49 & $\mathrm{i}$ & 63 \\
\hline $\mathrm{D}(+)$-Galactose & $\mathrm{i}$ & 29 & ns & 104 & $\mathrm{i}$ & 67 & $\mathrm{i}$ & 29 & $\mathrm{~ns}$ & 79 & $\mathrm{i}$ & 21 & $\mathrm{i}$ & 77 & $\mathrm{i}$ & 41 & $\mathrm{i}$ & 50 \\
\hline $\mathrm{D}(+)$-Mannose & $\mathrm{i}$ & 27 & $\mathrm{i}$ & 20 & $\mathrm{i}$ & 26 & $\mathrm{i}$ & 31 & $\mathrm{i}$ & 43 & $\mathrm{i}$ & 25 & $\mathrm{i}$ & 47 & $\mathrm{~ns}$ & 92 & $\mathrm{i}$ & 43 \\
\hline L-Rhamnose & $\mathrm{i}$ & 50 & ns & 97 & ns & 80 & $\mathrm{i}$ & 36 & $\mathrm{i}$ & 65 & $\mathrm{i}$ & 51 & $\mathrm{i}$ & 69 & $\mathrm{e}$ & 146 & $\mathrm{i}$ & 59 \\
\hline $\begin{array}{l}\text { D-Glucuronic } \\
\text { acid }\end{array}$ & $\mathrm{e}$ & 204 & $\mathrm{i}$ & 49 & $\mathrm{e}$ & 262 & e & 487 & e & 292 & $\mathrm{i}$ & 16 & e & 1786 & e & 262 & e & 279 \\
\hline
\end{tabular}

Table 6. Comparison of matrix effects during two years of biofilm study showing changes in levels of FITC-labelled lectin binding and effects of carbohydrate inhibition

i, Inhibited; e, enhanced; ns, not significantly different.

\begin{tabular}{|c|c|c|c|c|c|c|c|c|c|c|c|c|}
\hline \multirow[t]{3}{*}{ Carbohydrate } & \multicolumn{4}{|c|}{ Tet. purpureas } & \multicolumn{4}{|c|}{ A. hypogaea } & \multicolumn{4}{|c|}{ U. europaeus } \\
\hline & \multicolumn{2}{|c|}{1997} & \multicolumn{2}{|c|}{1998} & \multicolumn{2}{|c|}{1997} & \multicolumn{2}{|c|}{1998} & \multicolumn{2}{|c|}{1997} & \multicolumn{2}{|c|}{1998} \\
\hline & $P=0.05$ & $\begin{array}{c}\% \text { of } \\
\text { control }\end{array}$ & $P=0.05$ & $\begin{array}{c}\% \text { of } \\
\text { control }\end{array}$ & $P=0 \cdot 05$ & $\begin{array}{c}\% \text { of } \\
\text { control }\end{array}$ & $P=0.05$ & $\begin{array}{l}\% \text { of } \\
\text { control }\end{array}$ & $P=0.05$ & $\begin{array}{c}\% \text { of } \\
\text { control }\end{array}$ & $P=0.05$ & $\begin{array}{c}\% \text { of } \\
\text { control }\end{array}$ \\
\hline & \multicolumn{2}{|c|}{ LSD $=29$} & \multicolumn{2}{|c|}{$\mathrm{LSD}=26$} & \multicolumn{2}{|c|}{$\mathrm{LSD}=26$} & \multicolumn{2}{|c|}{$\mathrm{LSD}=11$} & \multicolumn{2}{|c|}{ LSD $=17$} & \multicolumn{2}{|c|}{ LSD $=8$ or $" 13$} \\
\hline $\mathrm{d}(-)$-Arabinose & $\mathrm{i}$ & 28 & $\mathrm{i}$ & 39 & $\mathrm{i}$ & 61 & $\mathrm{i}$ & 87 & $\mathrm{i}$ & 44 & $\mathrm{i}$ & 13 \\
\hline $\mathrm{L}(-)$-Fucose & $\mathrm{i}$ & 23 & $\mathrm{i}$ & 33 & $\mathrm{i}$ & 63 & $\mathrm{i}$ & 21 & $\mathrm{i}$ & 21 & ${ }^{*} \mathrm{i}$ & 30 \\
\hline $\mathrm{D}(+)$-Galactose & $\mathrm{i}$ & 67 & ns & 125 & $\mathrm{i}$ & 50 & $\mathrm{i}$ & 60 & $\mathrm{i}$ & 77 & $* \mathrm{e}$ & 119 \\
\hline $\mathrm{D}(+)$-Glucose & $\mathrm{i}$ & 40 & $\mathrm{i}$ & 42 & $\mathrm{i}$ & 29 & $\mathrm{i}$ & 85 & i & 29 & "e & 131 \\
\hline $\mathrm{D}(+)$-Mannose & $\mathrm{i}$ & 26 & ns & 77 & $\mathrm{i}$ & 43 & e & 154 & $\mathrm{i}$ & 47 & "e & 124 \\
\hline L-Rhamnose & ns & 80 & $\mathrm{i}$ & 67 & $\mathrm{i}$ & 59 & $\mathrm{i}$ & 56 & $\mathrm{i}$ & 69 & $\mathrm{e}$ & 115 \\
\hline
\end{tabular}

in the form of polysaccharides as part of the EPS matrix in biofilm systems. This type of signal has a more cloudlike appearance and is usually associated with microcolonies and cell clusters (Fig. 3a, e).

In general, the specificity of lectins is ascribed to the manufacturer (i.e. Sigma, Molecular Probes, EY Laboratories) and is based on the influence of lectins on blood cell agglutination. Therefore, lectin specificities are indicated in most publications as for example, Tri. vulgaris and Banderia simplicifolia are lectins specific for $\mathrm{N}$-acetylglucosamine, and $U$. europeaus is specific for L-fucose (see for example, Merker \& Smit, 1988; Michael \& Smith, 1995; Quintero \& Weiner, 1995; Hood \& Schmidt, 1996; Lawrence et al., 1998a; Neu \& Lawrence, 1997; Wolfaardt et al., 1998). In an almost unique case, Quintero \& Weiner (1995) used a haemagglutination assay with a purified bacterial EPS to demonstrate the specific binding of Baubinia purpurea lectin to the capsule of the bacterial strain MHS-3. However, such confirmation may be virtually impossible for complex biofilm matrices. In the present study we applied a simple assay using a relatively high con- centration of inhibitory carbohydrate (Table 3). The concentrations were within the range used in haemagglutination assays and those used by other authors to assess inhibition of lectin binding in other microbial systems (Merker \& Smit, 1988; Quintero \& Weiner, 1995; Michael \& Smith, 1995). Although a range of evaluation techniques have been used to assess lectin binding in microbial studies such as flow cytometry, electron microscopy and enzyme-linked immunoassays, the most common method of examining lectin binding has been standard epifluorescence microscopy and visual scoring of binding (Merker \& Smit, 1988; Michael \& Smith, 1995). We adapted the quantitative method of Wolfaardt et al. (1998) involving the application of CLSM coupled with fluor-conjugated lectins to rapidly and quantitatively probe the spatial relationships of EPS components within these lotic biofilm communities. In this system there were sufficient quantities of glycoconjugates to be easily visualized using CLSM. The advantages of this approach are greater sensitivity than the dark-adapted eye, and the images can be collected under standardized conditions of specimen preparation (lectin concentration, incubation conditions), image 
collection (laser power, voltage, gain, pinhole) and digital image analysis techniques. We also introduced the concept of a standardized method for quantitative analysis and expression of lectin binding as percentage of ICBA which includes both binding and intensity of binding, allowing statistical evaluation of treatment effects on lectin binding.

\section{Influence of the fluor conjugate}

Although it is generally assumed that conjugation with a fluor does not influence the specificity of a lectin, it is apparent from the manufacturers' data sheets that affinities as indicated by level of carbohydrate required for inhibition are influenced by both the presence and the nature of the fluor. In the present study we showed that all three fluorescent labels (FITC, TRITC and CY5) tested are not equally well suited for lectin-binding analysis in complex environmental systems. CY5labelled lectins are not ideal due to their emission in the far-red part of the spectrum which overlaps with the autofluorescence signal of chlorophyll-containing organisms, e.g. algae (Lawrence et al., 1998a). For TRITC-labelled lectins used in the inhibition experiments the expected decrease in signal with increasing sugar concentrations was not found. This was in contrast to experiments with FITC-labelled lectins where a clear decrease in signal was found when selected sugar concentrations were increased. This has, to the authors' knowledge, not been reported in the literature as other authors have attempted to confirm the identity of glycoconjugate binding sites through fairly limited inhibition studies. For example, Merker \& Smit (1988) demonstrated inhibition of binding of Tri. vulgarisFITC lectin to Caulobacter holdfasts by $\mathrm{N}$-acetylglucosamine monomers and oligomers. They determined that trimers were most effective in inhibition of lectin binding and suggested that this indicated the presence of stretches of contiguous $\mathrm{N}$-acetylglucosamine residues in holdfast material. Michael \& Smith (1995) demonstrated inhibition of C. ensiformis-FITC with $\alpha$-methyl D-mannoside. Our observations indicated that FITC-conjugated lectins exhibited binding patterns closer to the predicted outcomes when used in the biofilm systems. Thus, particularly with regard to interpretation of EPS chemistry, FITC-conjugated lectins may be the better choice to stain carbohydrate structures in biofilm systems. The interpretation of binding by CY5- and TRITC-labelled lectins may be confounded by the fact that the molecules are charged and that TRITC is zwitterionic in nature. This ionic character may have an effect on the lectin binding interaction with biofilm components. For example, the TRITC lectins often show extensive general binding to biofilm material with little apparent localization, consistent with non-specific binding as noted in a pure culture biofilm study (Johnsen et al., 2000).

\section{Lectin specificity in the biofilm matrix}

The effect of carbohydrate inhibition on lectin binding was tested with carbohydrates that have been indicated by the supplier to inhibit lectin binding. Lectin specificity has been largely based on the results of inhibition of haemagglutination with a specific range of carbohydrates. As biofilms contain a broad range of polysaccharide compounds including a large variety of chemical structures containing carbohydrates with the following features: neutral sugars, uronic acids, amino sugars, acetylated and methylated as well as many other residues (Kenne \& Lindberg, 1983; Sutherland, 1996; Lindberg, 1990; Sanford et al., 1995), additional inhibition studies were deemed necessary. A variety of other carbohydrates were selected to test their effect on lectin binding in the biofilm matrix. The data showed a complex pattern of inhibition, enhancement and no effect of the inhibiting carbohydrate, which was further confounded by the nature of fluor conjugated to the lectin molecule (Tables 1, 2, 4 and 5). Carbohydrate inhibition patterns for specific lectins were in general broader than indicated by the existing database. For example, although $U$. europeaus-FITC binding was inhibited by fucose as expected, significant reductions were also observed in the presence of arabinose, fructose, glucuronic acid, melibiose, methyl $\alpha$-pyrannoside, raffinose, glucose, mannose, galactose and rhamnose. Furthermore, with several of the 'non-lectinspecific' carbohydrates a surprising enhancement of lectin binding was found. Similar observations were made during experiments using lectins and carbohydrates in ELISA tests (T. Bog-Hanson, personal communication). The enhancement of lectin binding may be simply based on the inadequacy of existing databases regarding the range of carbohydrates showing interactions with lectins. Alternatively, the enhancement of lectin binding may be due to the presence of multiple carbohydrate binding sites. The addition of a specific carbohydrate may focus the second binding site and thereby may result in a higher binding affinity for another carbohydrate. This may provide a partial explanation for the observations summarized in Table 6 showing the changes in impact of carbohydrates between the 1997 and 1998 biofilms, where the same carbohydrate was observed to inhibit lectin binding in one year and enhance it in another. These shifts presumably reflect changes in EPS chemistry present in biofilms of different age, history etc. Consequently, lectin binding will be different and thus inhibiting monocarbohydrates may act differently during inhibition tests. Furthermore, the effect may be influenced by the non-carbohydrate binding site of the lectin which may recognize protein in the biofilm matrix (Ochoa et al., 1981; Barondes, 1988; Sharon \& Lis, 1989; Elgavish \& Shaanan, 1997). Our observations on the binding of Tetragonolobus and Ulex lectins, both with specificity for fucose, indicate that relative affinity for binding sites may be an important factor during multiple lectin staining. In this case Tet. purpureas-TRITC lectin has a 10-1000-fold higher affinity according to the suppliers' data sheet and in our study substantially alters the binding pattern of UEA-I-FITC. These observations indicate that a test series using an extensive range of relevant carbohydrates is required to fully evaluate the 
binding characteristics of a lectin prior to selection of a panel of lectins for analysis of biofilms. The determination of a relevant or focused carbohydrate inhibition panel may also require more extensive chemical characterization of the EPS matrix prior to in situ analyses using lectin techniques.

The results of the carbohydrate inhibition experiments also indicated that the lectins from Tri. vulgaris, A. hypogaea and L. polyphemus (given the wide range of carbohydrates that inhibit their binding in biofilms) may be useful as general EPS stains. Lawrence et al. (1998a) previously suggested that Tri. vulgaris-FITC or -TRITC may act as a general EPS probe for river biofilms.

\section{Role of interactions between lectins}

CLSM provides the opportunity to carry out multiple staining. Therefore it is important to assess the effects of interactions between lectins prior to multiple staining experiments. In experiments with dual-lectin staining, the order of lectin addition as well as the specific fluorescent labels were varied. Experiments evaluating the effect of order of addition indicated that the presence of one lectin may impact positively, negatively or have no effect on the binding of any subsequent lectin. These observations may be explained by a number of factors: (i) the differences in molecular mass and thereby the different mobility of the lectins (Lawrence et al., 1994; De Beer et al., 1997); (ii) the net charge of the lectin/ fluorochrome combination may also exclude or provide additional binding sites for subsequent lectins; (iii) the binding of the first lectin may also result in the masking of specific regions of mono-/di-/oligo-saccharides in the matrix by creating new targets that are recognized by subsequent lectins; (iv) the first lectin may simply provide binding sites for the subsequent lectin. For example, we observed formation of precipitates when C. ensiformis-TRITC was combined with Abrus precatorius-FITC lectin, indicating a strong reaction between the probes. In the case of enhancement of binding of $U$. europeaus-FITC by the presence of Tet. purpureas-TRITC (Tables 1 and 2), it may be that the TRITC-labelled lectin had created an altered target for the second lectin. In addition, the number and types of binding sites (carbohydrate and protein) and the relative binding affinity of the lectins for certain mono-/di/oligo-saccharides may also have an effect on multiplelectin binding. There are only a few cases where the interaction of the lectin with its carbohydrate target is well understood (e.g. Gohier et al., 1996). Thus it is important to assess the potential for lectin interactions prior to any multiple-labelling experiments. Indeed in some cases, lectin interactions may preclude their combined application.

\section{Lectin selection}

The lectins described in the literature are isolated mainly from plants and other eukaryotic organisms (Brooks et al., 1997; Van Damme et al., 1997; Singh et al., 1999).
These types of lectins may not be the ideal lectin source for probing the EPS matrix within environmental microbial biofilm systems. In general it may be more appropriate to apply bacterial- or algal-specific lectins, which may have direct access to the typical bacterial or algal glycoconjugates present in biofilm systems. These may be lectins specific for certain unique monosaccharides, a typical di-/oligosaccharide sequence within a repeating unit or even for a certain type of polysaccharide e.g. alginate or emulsan (Sutherland, 1996).

To utilize lectin-binding analysis for chemical characterization of biofilms, the complete carbohydrate inhibition spectrum of a given lectin should be known. However, this is generally not the case as the standard catalogue lectins are, according to the data sheet, tested only against a few carbohydrates. These carbohydrates are usually those which are important for cell biological research and they may not necessarily be present in the EPS of natural biofilms. In addition, other specific glycoconjugates may be unique to bacteria and biofilms such as, for example, alginate (Christensen, 1999). As a consequence, each biofilm system should be tested against a well selected range of lectins with well defined inhibition patterns for the matrix under study. Furthermore, knowledge about the secondary carbohydrate binding specificity of the lectin may be important for the understanding of their binding behaviour. This binding specificity may be for the same or another carbohydrate (Barondes, 1988; Reeke \& Becker, 1988; Weiss \& Drickamer, 1996).

In conclusion, lectin-binding analysis may be a suitable in situ technique to probe microbial biofilm systems for glycoconjugate distribution. However, each system has to be tested against a set of different lectins to exclude some of the above-mentioned uncertainties. Apart from the carbohydrate specificity, the secondary specificity for non-carbohydrates (e.g. proteins) should also be known. Additional uncertainties arise from the nature of the complex biofilm matrix including the absence of a true target for the lectin employed, the enormous variety of potential monosaccharide combinations, the presence of many cell surface types in biofilms, diversity of eukaryotic and prokaryotic EPS types and the presence of confounding biofilm components such as humic compounds. Further uncertainties arise from the properties of the lectin; these include the effect of the fluorescent label, the actual chemistry of the fluorescent label, the influence of fluor conjugation on the active site of the lectin and the possibility of either charged, hydrophobic or other non-specific interactions. Nevertheless, in opposition to the wet chemistry approach, the lectin approach is able to examine the fully hydrated EPS matrix in environmental biofilm systems for chemical heterogeneities without the need of isolating single polysaccharides. Clearly there is also a need for the chemical characterization of complex biofilm matrices. In this respect, the lectins currently available may be a valuable tool to estimate the glycoconjugate distribution in biofilm systems in complex natural as well as in 
artificial environments. This information is important for understanding the sorption properties of the EPS in relation to, for example, nutrients as well as elemental and organic contaminants. The isolation and characterization of new lectins, as suggested, may provide in the future the ultimate probes to unequivocally detect biofilm specific glycoconjugate distribution in fully hydrated and complex biofilm systems.

\section{ACKNOWLEDGEMENTS}

This work was supported by the Canadian-German Agreement on scientific and research co-operation (grants ENV 46/2, KAN 034/98 ENV), the National Water Research Institute, Environment Canada and the UFZ Centre for Environmental Research, Germany. Olaf Büttner (UFZ) is gratefully acknowledged for discussions regarding calculations and statistical analysis of data.

\section{REFERENCES}

Barondes, S. H. (1988). Bifunctional properties of lectins: lectins redefined. Trends Biochem Sci 13, 480-482.

Brooks, S. A., Leathem, A. J. C. \& Schuhmacher, U. (1997). Lectin Histochemistry: a Consise Practical Handbook. Oxford: Bios Scientific Publishers.

Christensen, B. E. (1999). Physical and chemical properties of extracellular polysaccharides associated with biofilms and related systems. In Microbial Extracellular Polymeric Substances: Characterization, Structure and Function, pp. 143-154. Edited by J. Wingender, T. R. Neu \& H.-C. Flemming. Berlin: Springer.

Cooksey, K. E. (1992). Extracellular polymers in biofilms. In Biofilms - Science and Technology. NATO ASI Series, vol. 223, pp. 137-147. Edited by L. F. Melo, T. R. Bott, M. Fletcher \& B. Capdeville. Dordrecht: Kluwer Academic Publishers.

De Beer, D., Stoodley, P. \& Lewandowski, Z. (1997). Measurement of local diffusion coefficients in biofilms by microinjection and confocal microscopy. Biotechnol Bioeng 53, 151-158.

Elgavish, S. \& Shaanan, B. (1997). Lectin-carbohydrate interactions: different folds, common recognition principles. Trends Biochem Sci 22, 462-467.

Flemming, H.-C., Schmitt, J. \& Marshall, K. C. (1996). Sorption properties in biofilms. In Sediment and Toxic Substances, pp. 115-157. Edited by W. Calmano \& U. Förstner. Berlin: Springer.

Gohier, A., Espinosa, J. F., Jimenez-Barbero, J., Carrupt, P.-A., Perez, S. \& Imberty, A. (1996). Knowledge-based modeling of a legume lectin and docking of the carbohydrate ligand: the Ulex europaeus lectin I and its interaction with fucose. J Mol Graph 14, 322-327.

Hood, M. A. \& Schmidt, J. M. (1996). The examination of Seliberia stellata exopolymers using lectin assays. Microb Ecol 31, 281-290.

Johnsen, A. R., Hausner, M., Schnell, A. \& Wuertz, S. (2000). Evaluation of fluorescently labeled lectins for noninvasive localization of extracellular polymeric substances in Sphingomonas biofilms. Appl Environ Microbiol 66, 3487-3491.

Jones, A. H., Lee, C.-C., Moncla, B. J., Robinovitch, M. R. \& Birdsell, D. C. (1986). Surface localization of sialic acid on Actinomyces viscosus. J Gen Microbiol 132, 3381-3391.

Kenne, L. \& Lindberg, B. (1983). Bacterial polysaccharides. In The Polysaccharides, vol. 2, pp. 287-363. Edited by G. O. Aspinall. New York: Academic Press.
Lawrence, J. R., Wolfaardt, G. M. \& Korber, D. R. (1994). Monitoring diffusion in biofilm matrices using scanning confocal laser microscopy. Appl Environ Microbiol 60, 1166-1173.

Lawrence, J. R., Neu, T. R. \& Swerhone, G. D. W. (1998a). Application of multiple parameter imaging for the quantification of algal, bacterial and exopolymer components of microbial biofilms. J Microbiol Methods 32, 253-261.

Lawrence, J. R., Wolfaardt, G. M. \& Neu, T. R. (1998b). The study of biofilms using confocal laser scanning microscopy. In Digital Analysis of Microbes: Imaging, Morphometry, Fluorometry and Motility Techniques and Applications. Modern Microbiological Methods Series, pp. 431-465. Edited by M. H. F. Wilkinson \& F. Schut. Chichester: Wiley.

Liener, I. E., Sharon, N. \& Goldstein, I. J. (editors) (1986). The Lectins: Properties, Functions and Applications in Biology and Medicine. Orlando, FL: Academic Press.

Lindberg, B. (1990). Components of bacterial polysaccharides. Adv Carbohydr Chem Biochem 48, 279-318.

Merker, R. I. \& Smit, J. (1988). Characterization of the adhesive holdfast of marine and freshwater Caulobacters. Appl Environ Microbiol 54, 2078-2085.

Michael, T. \& Smith, C. M. (1995). Lectins probe molecular films in biofouling: characterization of early films on non-living and living surfaces. Mar Ecol Progr Ser 119, 229-236.

Morioka, H., Tachibana, M. \& Suganuma, A. (1987). Ultrastructural localization of carbohydrates on thin sections of Staphylococcus aureus with silver methenamine and wheat germ agglutinin-gold complex. J Bacteriol 169, 1358-1362.

Neu, T. R. (1994). The challenge to analyse extracellular polymers in biofilms. In Microbial Mats: Structure, Development and Environmental Significance. NATO ASI Series G, vol. 35, pp. 221-227. Edited by L. J. Stal \& P. Caumette. Berlin: Springer.

Neu, T. R. (1996). Significance of bacterial surface-active compounds in interaction of bacteria with interfaces. Microbiol Rev 60, 151-166.

Neu, T. R. (2000). In situ cell and glycoconjugate distribution of river snow as studied by confocal laser scanning microscopy. Aquat Microb Ecol 21, 85-95.

Neu, T. R. \& Lawrence, J. R. (1997). Development and structure of microbial biofilms in river water studied by confocal laser scanning microscopy. FEMS Microbiol Ecol 24, 11-25.

Neu, T. R. \& Lawrence, J. R. (1999). Lectin-binding analysis in biofilm systems. Methods Enzymol 310, 145-152.

Neu, T. R. \& Marshall, K. C. (1990). Bacterial polymers: physicochemical aspects of their interaction at interfaces. J Biomat Appl 5, 107-133.

Neu, T. R. \& Marshall, K. C. (1991). Microbial 'footprints' - a new approach to adhesive polymers. Biofouling 3, 101-112.

Nielsen, P. H. \& Jahn, A. (1999). Extraction of EPS. In Microbial Extracellular Polymeric Substances: Characterization, Structure and Function, pp. 49-72. Edited by J. Wingender, T. R. Neu \& H.-C. Flemming. Berlin: Springer.

Ochoa, J.-L., Sierra, A. \& Cordoba, F. (1981). On the specificity and hydrophobicity of lectins. In Lectins - Biology, Biochemistry, Clinical Biochemistry, vol. 1, pp. 73-80. Edited by T. C. BogHansen. Berlin: de Gruyter.

Ong, C. J., Wong, M. L. Y. \& Smit, J. (1990). Attachment of the adhesive holdfast organelle to the cellular stalk of Caulobacter crescentus. J Bacteriol 172, 1448-1456.

Quintero, E. J. \& Weiner, R. M. (1995). Evidence for the adhesive function of the exopolysaccharide of Hyphomonas strain MHS-3 
in its attachment to surfaces. Appl Environ Microbiol 61, 1897-1903.

Reeke, G. N. \& Becker, J. W. (1988). Carbohydrate-binding sites of plant lectins. Curr Top Microbiol Immunol 139, 35-58.

Sanford, B. A., Thomas, V. L., Mattingly, S. J., Ramsay, M. A. \& Miller, M. M. (1995). Lectin-biotin assay for slime present in in situ biofilm produced by Staphylococcus epidermis using transmission electron microscopy (TEM). J Ind Microbiol 15, 156-161.

Sharon, N. \& Lis, H. (1989). Lectins as cell recognition molecules. Science 246, 227-234.

Singh, R. S., Tiwary, A. K. \& Kennedy, J. F. (1999). Lectins: sources, activities and applications. Crit Rev Biotechnol 19, 145-178.

Sutherland, I. W. (1996). Extracellular polysaccharides. In Biotechnology, vol. 6: Products of Primary Metabolism, pp. 612-657. Edited by H.-J. Rehm, G. Reed, A. Pühler \& P. Stadler. Weinheim: VCH.

Thomas, V. L., Sanford, B. A., Moreno, R. \& Ramsay, M. A. (1997). Enzyme-linked lectin sorbent assay measures $\mathrm{N}$-acyl-D-glucosamine in matrix of biofilm produced by Staphylococcus epidermis. Curr Microbiol 35, 249-254.

Van Damme, E. J. M., Peumans, W. J., Pusztai, A. \& Bardocz, S. (editors) (1997). Handbook of Plant Lectins: Properties and Biomedical Applications. Chichester and New York: Wiley.

Vasse, J. M., Dazzo, F. B. \& Truchet, G. L. (1994). Re-examination of capsule development and lectin-binding sites on Rhizobium japonicum 3I1B110 by the glutaraldehyde/ruthenium red/uranyl acetate staining method. J Gen Microbiol 130, 3037-3047.

Weis, W. I. \& Drickamer, K. (1996). Structural basis of lectincarbohydrate recognition. Annu Rev Biochem 65, 441-473.

Wingender, J., Neu, T. R. \& Flemming, H.-C. (1999). What are bacterial extracellular polymeric substances? In Microbial Extracellular Polymeric Substances: Characterization, Structure and Function, pp. 1-19. Edited by J. Wingender, T. R. Neu \& H.-C. Flemming. Berlin: Springer.

Wolfaardt, G. M., Lawrence, J. R., Robarts, R. D. \& Caldwell, D. E. (1998). In situ characterization of biofilm exopolymers involved in the accumulation of chlorinated organics. Microb Ecol 35, 213-223.

Xiao, G. Q. \& Kino, G. S. (1987). A real time confocal scanning optical microscope. In Scanning Imaging Technology; SPIE Proceedings Series, vol. 809, pp. 107-113. Edited by T. Wilson \& L. Balk. Bellingham: International Society for Optical Engineering.

Yagoda-Shagam, J., Barton, L. L., Reed, W. P. \& Chiovetti, R. (1988). Fluorescein isothiocyanate-labeled lectin analysis of the surface of the nitrogen-fixing bacterium Azospirillum brasilense by flow cytometry. Appl Environ Microbiol 54, 1831-1837.

Received 22 May 2000; revised 9 October 2000; accepted 1 November 2000. 